\title{
Investigating spatial concentration of sustainable restaurants: It is all about good food!
}

\section{Margo P. M. Enthoven ${ }^{1}$ (D) . Aleid E. Brouwer ${ }^{2,3}$}

Received: 29 June 2018 / Accepted: 30 October 2019 / Published online: 9 November 2019

(C) The Author(s) 2019

\begin{abstract}
This research addresses the role of sustainable demand and psychological and cultural factors in the spatial concentration of sustainable SMEs. We analyze the spatial concentration of sustainable SMEs in the restaurant sector in the Netherlands. We argue that traditional agglomeration theories can partially explain spatial concentration of sustainable SMEs, but are not sufficient in explaining the sub-sector concentration of sustainable entrepreneurs. Demand, psychological and cultural factors could explain sub-sector concentration of sustainable restaurants. We use sustainable entrepreneurship theory to explain this difference. We analyze spatial concentration of sustainable SMEs in three ways. First, we investigate spatial concentration based on all individual locations of sustainable restaurants with an average nearest neighbor analysis. Second, we analyze spatial autocorrelation with use of the Moran's I statistic. Finally, we map the clustering of sustainable restaurants with a Getis-Ord Gi* analysis. We use sustainable restaurants as a percentage of conventional restaurants in a region in the Netherlands. While controlling for conventional clustering, we find a single large cluster of sustainable restaurants. Arguably, this clustering is caused by a spatial variation of demand and individual psychological traits of sustainable entrepreneurs, which together represent a regional culture of sustainable entrepreneurship.
\end{abstract}

\section{JEL Classification E71 · L26 · R12 · Q01}

Just as people cannot live without eating, so a business cannot live without profits. But most people don't live to eat, and neither must businesses live just to make profits. John Mackey (2015 p. 250).

Margo P. M. Enthoven

m.p.m.enthoven@rug.nl

Aleid E. Brouwer

a.e.brouwer@rug.nl

1 Center for Sustainable Entrepreneurship, Campus Fryslân, University of Groningen, Leeuwarden, The Netherlands

2 Faculty of Spatial Sciences, University of Groningen, Groningen, The Netherlands

3 Academy for International Business Administration, NHL Stenden University of Applied Sciences, Leeuwarden, The Netherlands 


\section{Introduction}

Businesses can be drivers of sustainable economic growth. However, businesses are now the main drivers of the greenhouse effect (CDP 2017), air pollution (EuroStat 2019) and deforestation (WWF 2016). A change toward more sustainability from within the business world can have a phenomenal effect on our future. The tourism and hospitality industry is one of the least sustainable economic sectors in the world. The negative effect of restaurants on the environment becomes a public concern (Gössling et al. 2009). Consumers become more and more environmentally conscious; therefore, the demand for sustainable products and services grows. As such, in the restaurant industry more effort is made to become more environmentally friendly (Xu and Jeong 2019). Raab et al. (2018) find that especially serving sustainable food as a core product attracts niche customers, whereas other, more ancillary, green practices have no influence on customer segmentation.

In this paper, we research the nature and location of sustainability specialization within an established sector: the restaurant sector. We analyze within-industry sustainability specialization of restaurants in the Netherlands. Our research analyzes the occurrence of within-industry specialization on sustainable development, so that we can unravel the spatial factors for sustainable development by businesses. We show that sustainable entrepreneurship is not spatially blind and that locality needs to be taken into account by sustainable entrepreneurs and policy makers. Our results provide key inputs to those who want to fuel a transition toward sustainable business practices.

In this research, we explain how and to what extent sustainability orientation of businesses leads to sub-sector clustering. Previous research in economic geography focused mostly on the spatial concentration of industrial sectors and agglomerations, while concentration at the sub-sectoral level is not explained. In research on sustainable entrepreneurship, the role of place is largely underemphasized (McKeever et al. 2015). Previous research does not address the role of established clusters on sustainable entrepreneurship. Furthermore, research on the context of sustainable entrepreneurship has focused mostly on institutions, while the embeddedness and interactions with geophysical space, social systems and territories have been overlooked (Muñoz and Cohen 2018). Existing research is mostly qualitative or conceptual and focuses on the cultural and social embeddedness of sustainable entrepreneurship (Shrivastava and Kennelly 2013; Kibler et al. 2015; Anderson and Obeng 2017). The role of existing economic structures has been discussed in an urban context (Cohen and Muñoz 2015), but there is little evidence on the role of the urban environment on sustainable entrepreneurship. One study analyzes the geographical factors of sustainable clustering organizations (Sunny and Shu 2019), but assumes clustering instead of analyzing it. Sunny and Shu (2019) analyze company cluster organizations and do not consider the locations of individual businesses. A focus on the location of individual businesses is key in advancing our knowledge on the spatial behavior of sustainable businesses. Such a focus can show how the individual business is influenced by its economic surroundings and answers the call for more research on the embeddedness and interactions with geophysical space, social systems and territories (Muñoz and Cohen 2018). Our study uses location 
data from the entire population of restaurants in the Netherlands and therefore assesses spatial concentration based on a complete national dataset.

Our contribution to academic literature is twofold. Firstly, we contribute to the field of sustainable entrepreneurship by providing insight into the nature of spatial concentration of sustainable entrepreneurs. We do this by analyzing the role of spatial concentration of the mother sector on sustainable entrepreneurship. Secondly, we contribute to the economic geography literature. We contribute by analyzing the occurrence of subsector spatial concentration. We add to central place theory (Christaller 1966; Plane 2016; Gaspar 2018) by discussing sub-sector clustering as a part of industry clustering. Additionally, a focus on sub-sectoral concentration is key to questions relating the spatial nature of sub-sectors focusing on, for instance, luxury goods, ethnic specializations and sustainability specializations.

Furthermore, our insights can be of importance to policy makers. We recommend that sustainable entrepreneurship should be stimulated within large specialized industrial clusters. Galkina and Hultman (2016) find that initiatives of sustainable entrepreneurial nature, even small-scale niches, can lead to collective progress toward more sustainable practices in politics and governance. Thus, we believe that sustainability initiatives should be supported for each industry, within that industry. Based on our research, we propose that sub-sectors of an industry experience concentration in the largest clusters of that industry.

\section{Theory}

This research focuses on sustainable restaurants and their spatial patterns from the perspective of sustainable entrepreneurship theory. The presence of opportunities together with entrepreneurial persons creates entrepreneurship (Venkataraman 1997). These opportunities exist in the daily environment of the entrepreneur, while the recognition of opportunities is an individual trait. Opportunity thus exists at the nexus between entrepreneur and environment and is as such dependent on individual factors and factors in the entrepreneur's environment (Shane and Venkataraman 2000). Our theoretical endeavors evolve around the interaction between entrepreneur and environment, in the nature of psychological and cultural traits. We discuss the literature on business clusters and sustainable entrepreneurship to explain why differences in sustainable subsectors can arise within the entire sector. Section 2.1 discusses differences between sustainable and conventional SMEs. Section 2.2 discusses spatial concentration in the restaurant sector.

\subsection{Sustainable entrepreneurship versus conventional entrepreneurship}

We argue that sustainable SMEs are different from conventional SMEs. We provide a description of these differences based on the sustainable entrepreneurship literature. Sustainable entrepreneurs are those entrepreneurs that are both environmentally and socially friendly and competitive in the market (Johnsen et al. 2018; Muñoz 
and Cohen 2018). Galkina and Hultman (2016) as well as Hanohov and Baldacchino (2018) describe it as to make a profit in the most sustainable manner.

The sustainable entrepreneur's main goals are societal transformation toward more sustainability, to encourage more sustainable behavior in both restaurateurs and consumers and at the same time making a profit (Daneke et al. 2010). Sustainable entrepreneurs see the need for social and ecological solutions as 'an opportunity' (Johnsen et al. 2018). A focus on ethical goals indicates that sustainable entrepreneurs are different from conventional entrepreneurs who can be sustainable for other reasons. Conventional entrepreneurs can adopt sustainability goals out of cost reduction, as a marketing strategy, because of strict legislation or push from institutions such as NGOs (Isaak 2002; Schick et al. 2002; Hart and Milstein 1999; Galkina and Hultman 2016). The lack of commitment to sustainability goals in these businesses once a green identity has been established is expected to lead to a minimal effort in greening (Galkina and Hultman 2016). Existing firms adopting corporate social responsibility goals or environmental goals are not considered sustainable entrepreneurs. Sustainable entrepreneurs are characterized by their sustainability goals from the start of their business. The sustainability issue is seen as an opportunity for new entrants (Johnsen et al. 2018).

The psychological approach to sustainable entrepreneurship research has found that individual values, attitudes, motivations and goals are key in determining sustainable entrepreneurship. Kuckertz and Wagner (2010) indicate that the influence of a sustainability orientation on entrepreneurial intentions is an important determinant for sustainable entrepreneurship. Hanohov and Baldacchino (2018) add to this a motivation to develop gains for others: altruism. Besides orientations, individual sustainability values to the entrepreneur are key in determining sustainable entrepreneurship (Gast et al. 2017; Spence et al. 2011; Patzelt and Shepherd 2011; Muñoz and Cohen 2018). Values are the beliefs and principles that guide an individual's behavior (Schwartz and Bilsky 1990). Individual values appear to be a stable factor in determining sustainable entrepreneurship across countries (Spence et al. 2011; Muñoz and Cohen 2018). Other psychological factors in determining sustainable entrepreneurship are sustainability identity (York et al. 2016), orientation (Kuckertz and Wagner 2010; Muñoz and Dimov 2015), motivations (Simon et al. 2013) and attitudes (Krueger 1998). Other factors include social factors; perceived social and business support, perceived social norms, perceived desirability and concern about social pressure are considered social drivers or restrictors for sustainable entrepreneurship (Muñoz and Dimov 2015; Krueger 1998; Muñoz and Cohen 2018). Furthermore, a perceived threat to the (individual) environment can trigger sustainable entrepreneurship (Patzelt and Shepherd 2011); Muñoz and Cohen (2018) describe this as the chance for individuals focused on sustainability issues to develop the skill to recognize opportunities for sustainable entrepreneurship.

Other individual factors determining sustainable entrepreneurship are sustainability skills and competences. Differences between conventional and sustainable entrepreneurial skills exist due to the importance of foresighted thinking for sustainable entrepreneurship (Lans et al. 2014). Other competences that determine successfulness of sustainable entrepreneurship are embracing diversity and systems thinking competence (Ploum et al. 2018). Besides skills and competences, sustainable 
entrepreneurs need communal and environmental knowledge (Gast et al. 2017). Thus, we find that sustainable entrepreneurs need sustainability-specific motivations, experience social pressure for sustainability and require specific sustainability competences. As such they differ from conventional entrepreneurs; however, the differences between sustainable and conventional entrepreneurs are not absolute but a question of degree rather than kind.

\subsection{Spatial concentration in the restaurant sector}

Neoclassical theories of clustering have been widely used to explain the spatial concentration of entrepreneurs (Van Oort 2007; Tran and Santarelli 2017; Brülhart and Mathys 2008; Schiff 2015). The MAR (Marshall, Arrow, Romer) theory on spatial concentration posits that sector-specific knowledge fosters regional economic development and growth (Romer 1986). Porter takes a sector-specific approach and argues that regional growth is fueled by same-industry, local competition (Delgado et al. 2010; Porter 1990). Finally, Jacobs (1969) takes a cross-sector approach and argues that regional growth is fueled by cross-industry shared ideas. Sector-specific effects are likely to occur for the restaurant sector, because restaurants ${ }^{1}$ need to ensure maximum exposure and grouping can maximize consumer interest (De Groot et al. 2016). We argue that neoclassical approaches to spatial concentration do not explain a potential spatial concentration of sustainable entrepreneurship. Sustainability occurs across all industries, while sustainability itself is not an industry, but a sub-sector. Therefore, approaches based on industry knowledge sharing, such as the MAR and Porter agglomeration economies, could explain spatial concentration of sustainable SMEs, but are insufficient in explaining the differences between sustainable and conventional concentration of SMEs. Besides industry-specific knowledge, sustainability knowledge, skills and shared values of sustainable entrepreneurs also come into play and may display a different locality than industry knowledge. Jacob's (1969) cross-industry focus and her emphasis on cross-industry shared knowledge could be applicable to a spatial concentration of sustainable entrepreneurs, even cross-industry. However, it does not explain why some places should have higher proportions of sustainable entrepreneurs as opposed to conventional entrepreneurs. We do not reject the value of the traditional agglomeration theories; however, we argue that additional explanations are needed to address clustering of sustainable entrepreneurship. Therefore, we focus on sustainable entrepreneurship in the restaurant sector as a sub-sector. The next section explores how we, based on the previously mentioned theories, can explain the spatial concentration of sustainable entrepreneurship as a sub-sector concentration. Therefore, we explore known psychological, social, and cultural and demand differences between sustainable and conventional entrepreneurs and link these to existing knowledge on clustering.

Psychological explanations for clustering focus on individual behavior of the entrepreneur in relationship to his/her environment. Huggins and Thompson (2017)

\footnotetext{
${ }^{1}$ For restaurants, we consider the following sub-sectors: restaurants and hotel-restaurants (NACE groups 55.3 and 55.5 and SBI groups 55101, 5610 and 56101).
} 
propose a framework in which psychology, culture and institutions influence human behavior and agency. Human behavior and agency consequently lead to urban and regional development; culture, they propose, is socio-spatial. There is an interaction between culture and psychology: A culture's values, norms and beliefs influence the individual's values, norms and beliefs, while the shared values, norms and beliefs of many individuals comprise a culture (Huggins and Thompson 2017).

The importance of social networks for entrepreneurship is highlighted by Saxenian (1996), who indicates that the face-to-face social interactions among and within firms and local institutions determine entrepreneurship. An entrepreneur's social environment is key in the decision to start a firm (Sternberg and Litzenberger 2004). Entrepreneurs gain knowledge from other actors through processes of information sharing in a social network. This happens when a network facilitates trust and network actors have similar norms and values (Durlauf and Fafchamps 2004; Huber 2009). When levels of trust are high and norms and values similar, social networks create social capital. Social capital is defined as a source of social control (Portes 2000). Social capital creates group identity and leads to the modification of behavior: 'Herding' effects have a converging effect on the group members' behavior. This is when all members of a social group start following the social norms of the group and act more alike. Through the herding process, social capital causes group behavior that can be different from the individual's initial intention (Durlauf and Fafchamps 2004). This herding effect raises an entrepreneurial group culture. An entrepreneurial group culture can lead to more individuals with entrepreneurial values and hence more entrepreneurs (Uhlaner and Thurik 2007). An addition is the transmission of entrepreneurial spirit through a role model (Laspita et al. 2012). If role models transfer entrepreneurial spirit, then role models foster other entrepreneurs in their vicinity. Multiple studies have found positive effects of both weak and strong ties on sustainable and social entrepreneurship, within the personal network and on the local and the national level (Bosma et al. 2016; De Lange 2016; Estrin et al. 2013).

Besides the positive effects of social capital on entrepreneurship, there is also a downside of social capital. There is a risk of conformity bias in tight groups, which restricts radical ideas. De Vaan (2011) indicates that the more social capital is present in a region, the less likely entrepreneurs are to start businesses in industries that remain unexploited in that region. Due to value convergence and social norm creation in social networks, some types of business are considered illegitimate. If sustainable entrepreneurship is considered to be in conflict with the social norm, there could be a lower incidence of sustainable entrepreneurship. A sustainable entrepreneur could, for instance, not be welcome in a network where classical business values are dominant. Differences in social capital between regions can generate differences in regional rates of sustainable entrepreneurship and thus potentially create sustainable clusters.

Another factor that can drive sustainable entrepreneurship is the demand of customers. Supply is driven by consumer demand, especially so in the service industry (Xu and Jeong 2019). Customers purchase goods and services to satisfy their desires and needs. Customer demand theory states that demand for specific goods changes over time. Businesses therefore need to supply new products or new versions of 
existing products to stimulate new demand (Larsson and Bowen 1989). Customers are not homogenous in their demand, but all have specific preferences, hence demand for specific products and services fluctuate (Thompson 1998). In other words, the customer demands what he/she wants to buy and where s/he wants to buy it (Baltas 2003). As such, businesses tend to adapt their product in line with consumer preferences in specific regions and locations (Etgar and Rachman-Moore 2010). Consumers are not evenly spread by demographic characteristics (e.g., age, gender, education level, income) over all locations within a country. For example, in urban areas the distribution over diverse age groups differs from the distribution over age groups in rural areas. Consequently, customer demand diversifies over regions, the geographical location of specific demographic traits. As such potention customers create the product differentiation offered by the supplier (Phillips and Peterson 2001), spaces of production (Zukin 1995).

Boterman (2018) studies the location of haute cuisine in the Netherlands and finds location patterns an over representation of haute cuisine in the major urban centers of the Netherlands. He argues that 'This largely overlaps with the general pattern of most consumption spaces in Amsterdam, which are also predominantly concentrated in the central parts of the city. This area is also frequented by the majority of tourists and visitors who also are typically cultural consumers' (p. 166) and explains this by 'two interrelated trends: (1) the general re-emergence of larger cities exemplified by their demographic and economic growth and (2) the rise of an urban middle class, often manifesting itself through processes of gentrification.'(p. 168). Similar processes can shape the location patterns of sustainable restaurants from a consumer's demand perspective.

Entrepreneurship culture can be understood as an informal institution that comprises norms, values and codes of conduct (Kibler et al. 2014; Andersson and Larsson 2016). Some of these values are independence, individualism and achievement (Uhlaner and Thurik 2007). Generally, we discuss culture as the values, beliefs and expected behaviors that are sufficiently common across people within a given geographical region to be considered as shared (Hofstede 2001). The entrepreneurial culture is seen as the environment that shapes the level playing field, a collective programming of the mind in which the underlying value system is oriented toward entrepreneurial behavior (Beugelsdijk 2007). There is some evidence that social entrepreneurship is influenced differently by culture than conventional entrepreneurship (Hechavarría 2016). For instance, countries with traditional values have higher levels of commercial entrepreneurship, whereas countries with secular-rational values have higher social entrepreneurship rates. Cohen (2006) argues that culture is crucial in facilitating a cluster of sustainability initiatives and innovations. For instance, local knowledge and practices influence a community's sustainability agenda, while the quality and quantity of outdoor recreation can also develop a community that cares for the environment.

Furthermore, there are likely effects of existing sustainable peers in a region. Following the notion that role models can pass on entrepreneurial spirit (Laspita et al. 2012), role models can also pass on a sustainability spirit. Because sustainable entrepreneurs have different values, beliefs and competences than conventional entrepreneurs (see Sect. 2.1.), they need different peers to learn from. Also, social 
networks containing sustainability professionals could generate spillovers of knowledge that could lead to the startup of new sustainable ventures (Acs et al. 2009). Consequently, the presence of peers and social networks with specific knowledge, competences, beliefs and values on sustainability can inspire and educate new sustainable entrepreneurs. Wherever such peers and social networks are located, they could give rise to a sustainable entrepreneurship culture on a higher spatial scale.

Litaa et al. (2014) find that customers are increasingly willing to pay extra for receiving environmentally friendly products. Litaa et al. (2014) also find that consumers with higher incomes and education levels were more likely to visit sustainable restaurants. Research from Raab et al. (2018) suggests that even though only $40 \%$ of the people know about the negative environmental impact of restaurants, $78 \%$ is willing to pay a bonus to eat in a sustainable restaurant. More women tend to pay the extra fee, but those men who are willing to pay an extra fee, pay on average a higher fee than women. Furthermore, the willingness to pay the sustainable bonus in restaurant is also related to higher education levels. Interesting is that especially the youngest age group and the lowest income group are willing to pay a higher fee than other demographic groups (Raab et al. 2018). Sarmiento and Hanandeh (2018) describe the eaters at sustainable restaurants as those people who have green lifestyles, earning a mid-income and are more likely to be young and female.

Concluding, the psychological, social and cultural level and customer demand have an impact on entrepreneurship and spatial concentration. The social and cultural levels of entrepreneurship are in part made up of the sum of psychological factors of individuals, but also change the individual's psychology. This can lead to behavior change and, possibly, entrepreneurship. Therefore, we argue that individual psychological traits, through social groups, through culture, create regional differences in entrepreneurship, where sustainable entrepreneurs may exhibit other patterns than conventional entrepreneurs. We believe that sustainable entrepreneurship clusters can arise due to the interplay of customer demand, psychological, social and cultural traits. We propose:

H1 Sustainable SMEs in the restaurant sector are spatially concentrated.

$H 2$ Sustainable SMEs in the restaurant sector are concentrated in other locations than conventional SMEs in the restaurant sector.

\section{Data and method}

This exploratory research uses secondary spatial data to assess the spatial concentration of sustainable SMEs. We used multiple spatial estimates to test spatial concentration of sustainable and conventional restaurants. First, the spatial concentration of sustainable SMEs is tested based on point data. Conventional SMEs and control factors are not included in this analysis. Second, the spatial concentration of sustainable SMEs as a percentage of conventional SMEs per region is tested. If spatial concentration occurs in both analyses, we can confirm that there is a different pattern of spatial concentration between sustainable and conventional restaurants in the Netherlands. Finally, we map spatial concentration to find where it occurs in the 
Netherlands and which factors could potentially explain this. The following section discusses the research context, sample and design used to determine spatial concentration of sustainable restaurants.

\subsection{Research context}

The focus of this research is on SMEs in the restaurant sector. Sustainable restaurants cater to a number of sustainable diets with different rationales. We base our guidelines for sustainable food on the dominant consumer perception of sustainable food and research on sustainable diets, as illustrated by the sustainable food guidelines of the Voedingscentrum (Centre for Nutrition) and Milieu Centraal (Environment Central) in the Netherlands (Voedingscentrum 2018; Milieucentraal 2018). The restaurants we consider sustainable are the restaurants that cater to the current perception of these institutions regarding sustainable food and sustainable diets. Our characterization depends on scientific evidence from food studies and on recent sustainable food trends (FAO 2006; Morawicki 2012; Garnett 2014; Voedingscentrum 2018; Milieucentraal 2018). Local, seasonal, vegetarian or vegan diets are more sustainable than the average western diet in relation to greenhouse gas emissions, overfishing, deforestation, desertification, over-fertilization and the accompanying ocean acidification, ocean dead zones and biodiversity loss (FAO 2006; Morawicki 2012; Garnett 2014). Organic food is produced without synthetic fertilizers and contributes to diversity of species and to a food system that is less sensitive to pests and other shocks (Hole et al. 2005); this is socially sustainable, because such shocks can have famine as a consequence. Furthermore, local, seasonal and organic food production promotes crop variety, which makes the global food system less susceptible to shocks and this promotes food security. Plant-based diets such as vegan and vegetarian diets promote social sustainability by using fewer resources for fodder (Morawicki 2012) and thereby free arable land for the battle against world hunger.

We consider vegan, organic, local and seasonal diets to be more sustainable than the conventional Western diet, in terms of social and environmental effects. Restaurants serving local, organic, seasonal, vegan and/or vegetarian food are therefore considered more sustainable than conventional restaurants in this research. The locations of restaurants serving mainly (over 50\%) vegan, vegetarian, seasonal, local or organic food are selected to determine spatial concentration of sustainable entrepreneurs in the restaurant sector. We chose to use $50 \%$, since this is the percentage of organic food a restaurant in the Netherlands has to serve for a silver organic certification (EKO-Keurmerk Foundation 2018).

\subsection{Sample}

The data used in this research consists of the locations of all restaurants in the Netherlands, including sustainable restaurants. These locations are part of the LISA dataset by the Dutch Chamber of Commerce, containing all businesses in the Netherlands in 2013. From all food and beverage outlets in the Netherlands, we include restaurants and hotel restaurants and exclude café's, catering services, canteens, 
ice-cream parlors and fast food restaurants. We manually browsed the largest restaurant booking and listing websites in the Netherlands. ${ }^{2}$ If a restaurant was listed as a local, seasonal, organic, sustainable, vegetarian or vegan restaurant, we visited their website to investigate their menu. We considered those restaurants serving at least $50 \%$ vegan, vegetarian and organic food as sustainable restaurants. The final manual selection of sustainable restaurants in the Netherlands consists of 591 out of 15,081 restaurants $(4 \%)$.

\subsection{Analysis}

The spatial analyses in this paper test whether sustainable entrepreneurship clusters differently than conventional entrepreneurship. We execute three clustering estimates on our spatial data. Our spatial data consists of the LISA dataset of 2013 (The Dutch chamber of Commerce dataset of all businesses), which contains the data of all Dutch restaurants and a manual selection of sustainable restaurants based on online restaurant listings and their menus. The spatial analysis consists of three steps for which we use the ArcMap software.

The first step of the analysis consists of an average nearest neighbor analysis to determine whether the location of restaurants to their nearest neighbor is significantly shorter than expected, given the size of the database and the surface of the Netherlands (Altman 1992):

$$
\mathrm{ANN}=\frac{\bar{D}_{\mathrm{O}}}{\bar{D}_{\mathrm{E}}}
$$

where $\bar{D}_{\mathrm{O}}$ is the observed mean distance between each feature and its nearest neighbor:

$$
\bar{D}_{O}=\frac{\sum_{i=1}^{n} d_{i}}{n}
$$

and $\bar{D}_{\mathrm{E}}$ is the expected mean distance for the features given in a random pattern:

$$
\bar{D}_{\mathrm{E}}=\frac{0.5}{\sqrt{n / A}}
$$

In the above equations, $d_{i}$ equals the distance between feature $i$ and its nearest neighboring feature, $n$ corresponds to the number of features, and $A$ is the area of a minimum enclosing rectangle around all features, or it's user-specified area value. The average neighbor $z$-score for the statistic is calculated as:

$$
z=\frac{\bar{D}_{\mathrm{O}}-\bar{D}_{\mathrm{E}}}{\mathrm{SE}}
$$

\footnotetext{
2 These websites include: www.thefork.nl (previously, www.iens.nl), www.bewustbiologisch.nl, www. happycow.com, www.friesstreekproduct.nl, www.lokaalenlekker.nl, www.foodlabzeeland.nl, www.eetnu .$n l$ (does not exist anymore), www.eko-horeca.nl and www.ecolage.nl.
} 
where

$$
\mathrm{SE}=\frac{0.26136}{\sqrt{n^{2} / A}}
$$

The null hypothesis of this analysis states that there is no spatial association among the realization of a variable on a location and its neighbors. The point data of the individual restaurants in the dataset are used for this analysis. We perform this analysis separately on the LISA data and the selection of sustainable restaurants.

Second, we aggregate the point data on a raster of so-called fishnet polygons, because polygon data is required for the following step. A raster in the shape of a fishnet is used to create square-shaped areas for the Netherlands, so that the regions we analyze all have the same shape and size except for border areas, which are cut off at the border. We calculate the share of sustainable restaurants in the polygon, by dividing the number of sustainable restaurants by the total number of restaurants. After aggregating our point data to polygons, we calculate a global Moran's I estimate of spatial autocorrelation:

$$
I=\frac{n}{S_{\mathrm{O}}} \frac{\sum_{i=1}^{n} \sum_{j=1}^{n} w_{i, j} z_{i} z_{j}}{\sum_{i=1}^{n} z_{i}^{2}}
$$

where $z_{i}$ is the deviation of an attribute for feature $i$ from its mean $\left(x_{i}-X\right), w_{i, j}$ is the spatial weight between feature $i$ and $j, n$ is equal to the total number of features, and $S_{O}$ is the aggregate of all spatial weights:

$$
S_{\mathrm{O}}=\sum_{i=1}^{n} \sum_{j=1}^{n} w_{i, j}
$$

The $Z_{\Gamma}$-score for the statistic is computed as:

$$
z_{I}=\frac{I-E[I]}{\sqrt{V[I]}}
$$

where

$$
\begin{gathered}
E[I]=-1 /(n-1) \\
\mathrm{V}[I]=\mathrm{E}\left[I^{2}\right]-\mathrm{E}[I]^{2}
\end{gathered}
$$

This statistic determines whether the spatial data is randomly or non-randomly distributed by means of a Z-score (Moran 1950). Thus, this statistic determines the relatedness of a feature to its neighbors. A non-random distribution is an indication of dispersion or clustering. The null-hypothesis for this statistic is that the features are randomly distributed. It requires a defined distance to determine the distance at which features are considered neighbors. Around each feature, a distance band determines which other features are neighbors and which are not. We perform this 
analysis 30 times with different distance bands, to determine which distance band is most suitable for our data and our next analysis. For whichever distance the $z$-score is highest, that is where spatial processes promoting clustering are most pronounced. We use these peak distances as spatial weights in the final step: of our analysis.

For the third and final step, we use the Getis-Ord Gi* hot spot analysis to determine where hot spots of sustainable restaurants are located in the Netherlands (Getis and Ord 1992).

The Getis-Ord local statistic is given as:

$$
G_{i}^{*}=\frac{\sum_{j=1}^{n} w_{i, j} x_{j}-\bar{X} \sum_{j=1}^{n} w_{i, j}}{S \sqrt{\frac{\left[n \sum_{j=1}^{n} w_{i, j}^{2}-\left(\sum_{j=1}^{n} w_{i, j}\right)^{2}\right]}{n-1}}}
$$

where $x_{j}$ is the attribute value for feature $j, w_{i, j}$ is the spatial weight between feature $i$ and $j, n$ is equal to the total number of features and:

$$
\begin{gathered}
\bar{X}=\frac{\sum_{j=1}^{n} x_{j}}{n} \\
S=\sqrt{\frac{\sum_{j=1}^{n} x_{j}^{2}}{n}-(\bar{X})^{2}}
\end{gathered}
$$

The Getis-Ord Gi* statistic is a $z$-score. Again, we use the share of sustainable restaurants of total restaurants in a region. This statistic considers each feature in the context of its neighbor. It determines hot and cold spots: areas of spatial concentration and spatial dispersion. Hot and cold spots are determined based on the sum of a feature and its neighbors. It determines whether the value of a feature and those of its neighbors are significantly low or high in relation to the sum of all features in the dataset. A hot spot is found when multiple neighboring features are found to have high values. A cold spot is found when multiple neighboring features have low values. The statistic requires a spatial weight, which is determined by the values of a feature's neighbors. We determine which features are neighbors based on the global Moran's I statistic in step two. The distance at which the z-statistic of the Moran's I peaks is a suitable indicator of spatial weights. All features within the given distance band are included in the spatial weight. To control for the spatial dependency of features, we correct our analysis for a potential false discovery rate (FDR). Based on a false positivity estimate, the features with the weakest $p$ values are eliminated from the results (Caldas de Castro and Singer 2006).

By using the Moran's I and Getis-Ord Gi* statistic in conjunction, we use both global and local statistics. This allows us to detect spatial dependency on global and local levels, which verifies our result on multiple scales. Whereas the Moran's I detects clustering in the sample as a whole, the Getis-Ord Gi* statistic allows us to find local pockets of concentration (Getis and Ord 1992). Due to the nature of the analysis to use point data, there is no possibility to control for population 
and agglomeration effects. The consequent analysis is controlled for agglomeration effects and for localization effects from the conventional restaurant sector, by analyzing the number of sustainable restaurants as a percentage of the number of conventional restaurants in a region. Thus, we assume that the restaurant data is influenced by these forces. However, since we aim to find spatial concentration of a sub-sector, the agglomeration effects that apply to the restaurant sector also apply to the sub-sector. By analyzing the percentage of sustainable restaurants out of total restaurants, we control for the effects of agglomeration on the restaurant sector as a whole. Unfortunately, this does not allow us to differentiate between the effects of agglomeration on all restaurants versus the effects of agglomeration on sustainable restaurants.

\section{Results}

The LISA data is highly concentrated when not corrected for the population in a region. The nearest neighbor analysis on the LISA dataset indicates spatial concentration, $p<.001$. The sustainable restaurant selection shows a pattern of concentration as well, $p<.001$. Based on this analysis, we assume a spatial association between the features in the dataset. Therefore, hypothesis 1 is supported.

We use the Moran's I spatial autocorrelation analysis to indicate peaks in spatial concentration (see Fig. 1). We find a peak at $20 \mathrm{~km}$ and a peak at $38 \mathrm{~km}$. Furthermore, we find that the $z$-score declines from the beginning point of $13 \mathrm{~km}$ and increases again after $16 \mathrm{~km}$. We find that the $z$-score increases with distance, which is generally expected in a sample with spatial concentration. The peak distances are characteristic for the economic geography of the Netherlands as illustrated by Van Oort (2007), who considers a core-periphery structure of commuting in the Netherlands. The distances we found are in line with evidence for Jacobs' (1969) externalities in the Netherlands, in which inter-industrial externalities and competitiveness promote economic activity in agglomerations (Van Oort 2007). The peaks at 20 and $38 \mathrm{~km}$ are illustrative of center-periphery distances in the Netherlands, with the peak of $20 \mathrm{~km}$ for the most urbanized provinces and the peak of $38 \mathrm{~km}$ for the least urbanized provinces in the Netherlands.

Based on the results of the Moran's I spatial autocorrelation analysis (see Fig. 1), we perform the hot spot analysis with two distance bands. The distances of 20 and $38 \mathrm{~km}$ displayed peaks where the spatial processes promoting clustering are most pronounced. The first distance band includes all neighbors within a radius of $20 \mathrm{~km}$ and the second distance band includes all neighbors within $38 \mathrm{~km}$. The hot spot analysis finds a cluster of restaurants in the west of the Netherlands (see Figs. 2, 3 ). Figures 2 and 3 reflect the differences in the distance band, as the cluster with a distance band of $38 \mathrm{~km}$ is more expanded. However, the same areas are at the heart of both clusters. Our two analyses report the same cluster with different boundaries based on the scope of the area included in the analysis. The cluster is located in one of the most densely populated parts of the Netherlands and in the largest agglomeration of the Netherlands. These results could reflect a more general diversity of restaurants in the largest urban centers of the Netherlands (Schiff 2015). However, 
Spatial Autocorrelation by Distance

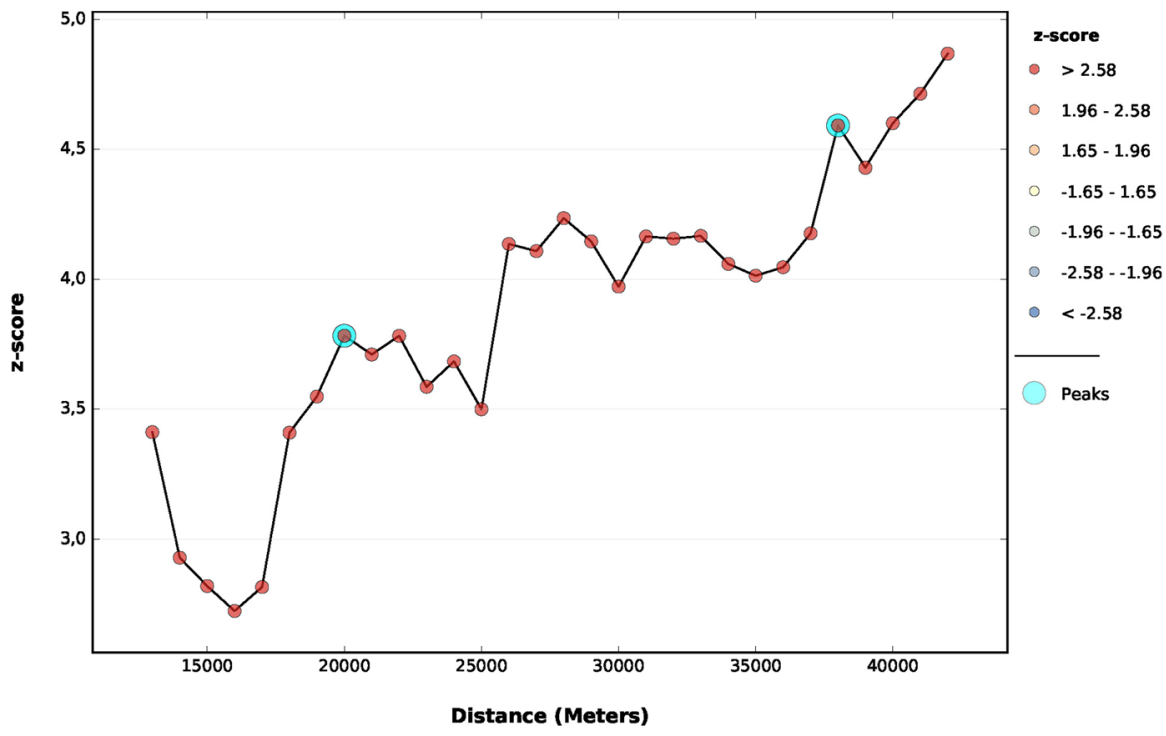

Fig. 1 Incremental spatial autocorrelation of sustainable restaurants

the differences in population size among the city of Amsterdam, where our cluster is found, and Rotterdam and The Hague, which are not covered by our cluster, is small: These cities have around 790.110, 616.260 and 502.055 inhabitants, respectively. A higher diversity in types of restaurants can be expected in urban areas (Schiff 2015); thus, the urban areas of the Netherlands could have higher shares of sustainable restaurants as a result of this diversity. However, we find that this is only the case for one of the larger urban centers: Amsterdam. Furthermore, we find that part of the cluster is located, in the Gooi en Vecht area. According to Boterman (2018), food consumption and the rise of haute cuisine in the Netherlands is the effect of a rise of an urban middle class. Sustainable consumption is also most prevalent among the urban middle class (Sarmiento and Hanandeh 2018). This is in line with what we find for Amsterdam. The Gooi en Vecht area, however, is less urban than the other cluster areas and is famous for being an upper-class living area. Therefore, the concentration there is not in line with Botermans (2018) findings of haute cuisine locations. We believe that the concentration we found in Gooi en Vecht might be explained by the high income of the inhabitants and a potential desire of upper-class individuals to eat healthy or trendy foods. We believe the inhabitants of this area might be more susceptible to trendy lifestyles, which could be related to their food consumption pattern. This is in line with the research by Litaa et al. (2014) that consumers with higher incomes are more likely to buy sustainable food. Because we find hot spots of spatial concentration of sustainable restaurants as a share of conventional restaurants, our second hypothesis is supported.

Interestingly, we do not find any cold spots with either of the distance bands. Within the center of the cluster, the regions have a percentage of sustainable 


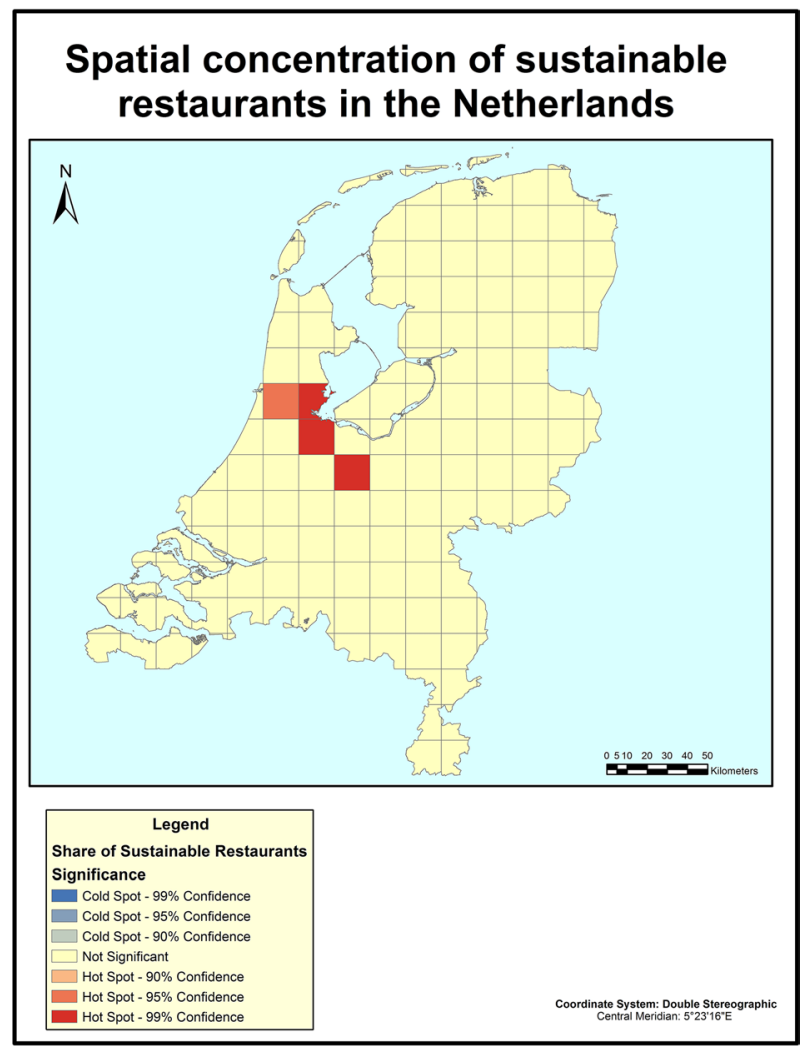

Fig. 2 Spatial concentrations of restaurants in the Netherlands (FDR corrected, distance band $20 \mathrm{~km}$ )

restaurants between three and seven. The median percentage of sustainable restaurants in the population, however, is $0.9 \%$. Due to this low percentage, low values are more common than high values. Therefore, we believe that we are less likely to find cold spots.

\section{Discussion and conclusion}

This paper considers whether sustainable restaurants have a different spatial pattern than conventional restaurants, and as such, investigates whether sub-sectors cluster within larger clusters of the entire industry. Our results show that there is a spatial concentration of sustainable SMEs and could indicate a difference in entrepreneurship culture in different areas of the Netherlands. The main contribution of this paper is the finding that sustainable entrepreneurs are influenced by the existing economic structures. We contribute to the literature on spatial concentration by showing that sub-sector clustering occurs for sustainable restaurants. This is in line with central place theory (Christaller 1966; Plane 2016; Gaspar 2018) and has 


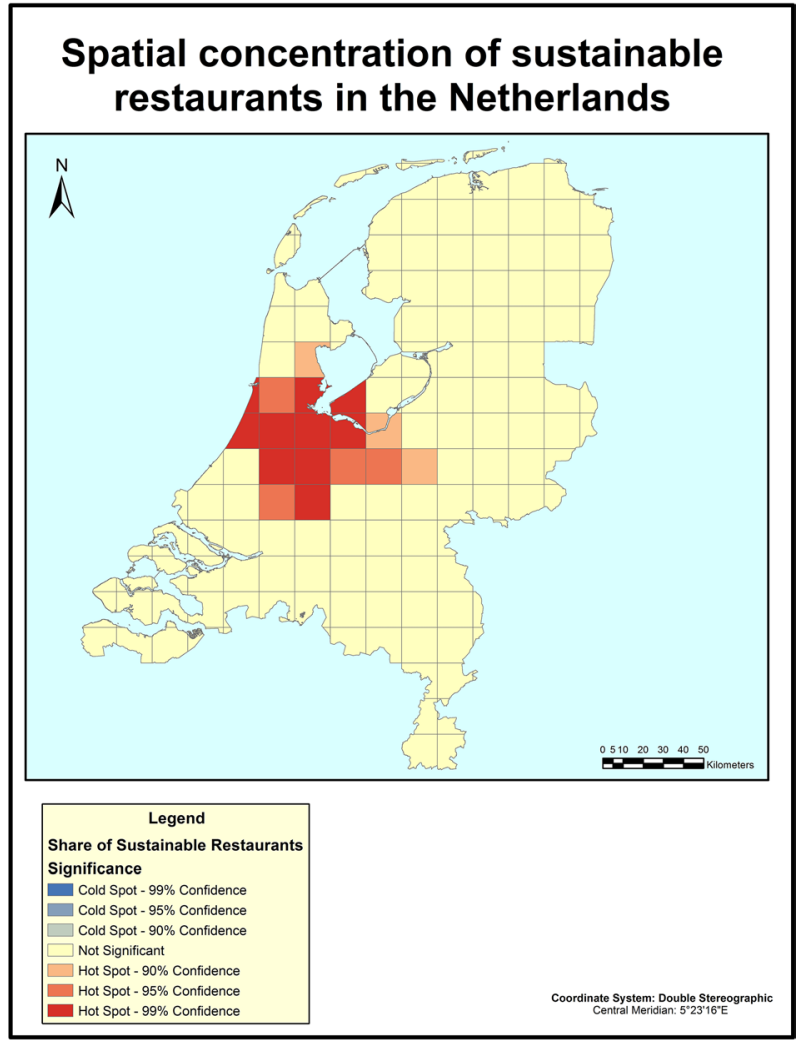

Fig. 3 Spatial concentrations of restaurants in the Netherlands (FDR corrected, distance band $38 \mathrm{~km}$ )

implications for sustainable sub-sectors and other sub-sectors, such as luxury or ethnic sub-sectors. We find evidence to support the idea of sub-sector sustainability clustering. Thus, there, where already the most restaurants are concentrated, is also where sustainable restaurants are concentrated. Within the largest industry cluster, sustainability clustering occurs as well. For smaller industry clusters, there is no sustainability clustering. Thus, we argue that large agglomerations are the most likely hub for the occurrence of sub-sector concentration. The largest agglomeration has the most diverse products and services and acts as a hub for the surrounding area (Christaller 1966). This includes the occurrence of sustainable businesses as a subsector. We specifically discuss how entrepreneurs with a focus on sustainability differ from conventional entrepreneurs and how this could give rise to specific spatial patterns. Other sub-sectors that exhibit differences in the psychology of the entrepreneurs, the demand of the customer or the culture compared to the larger sector could potentially also exhibit sub-sector clustering.

The sustainable cluster that we found contains Amsterdam and one of the wealthiest residential areas of the Netherlands, the Gooi en Vecht area (CBS 2015). Clustering does not occur in other large urban centers in the Netherlands. Thus, our results 
do not seem to suggest a diversification based on city size, as was found by Schiff (2015). Our findings are partially in line with Boterman (2018), who studies the location of Haute Cuisine in the Netherlands and finds similar location patterns as we do, with an overrepresentation of haute cuisine in the major urban centers of the Netherlands. We believe that the cluster we found could be the effect of a regional entrepreneurial culture that includes sustainability. Spatial variances in demand and in social capital are potential explanations for this indication of value-based spatial concentration (Bosma et al. 2016). Other explanations can be differences in entrepreneurial culture (Huggins and Thompson 2017) and entrepreneurial ecosystems (Cohen 2006). Businesses which focus on sustainability should be considered under influence of the economic structure their sector, while displaying sustainability-specific spatial behavior.

Our results imply that sustainable initiatives are best stimulated within already large clusters of that industry. Policy makers could use this result when aiming toward more sustainable behavior of entrepreneurs. In our case, the largest agglomeration and the largest industry cluster overlap. Larger agglomerations specifically can stimulate sustainability initiatives, because they serve as a market for all kinds of specializations. Thus, sustainability specializations are more likely to find a market in the largest agglomeration, of a country. For industries that benefit less from agglomeration economies, specializations, including sustainability specializations, are most likely to be found in the largest industry cluster.

Although the analysis is limited due to the small number of the sustainable restaurants in the data, it is a suitable sector for an analysis on sustainable SMEs. Larger sample sizes of sustainable entrepreneurs will likely not occur in other sectors. The findings from this research could be transferable to other types of sub-sector clustering. Furthermore, survivor bias could be in place due to a possible difference in survival rates of sustainable and conventional restaurants. Uncertainty concerning survival rates leaves it unclear whether some areas have a more successful sustainable start-up scene or whether there is a higher survival rate of sustainable businesses. It would be interesting for future research to determine whether spatial concentration of sustainable SMEs is due to psychological, cultural or demand effects. We believe that in-depth qualitative research and place-sensitive survey research could provide insights into the restaurateurs' perception of their behavioral, social and cultural environment.

Open Access This article is distributed under the terms of the Creative Commons Attribution 4.0 International License (http://creativecommons.org/licenses/by/4.0/), which permits unrestricted use, distribution, and reproduction in any medium, provided you give appropriate credit to the original author(s) and the source, provide a link to the Creative Commons license, and indicate if changes were made.

\section{References}

Acs Z, Braunerhjelm P, Audretsch D, Carlsson B (2009) The knowledge spillover theory of entrepreneurship. Small Bus Econ 32(1):15-30

Altman NS (1992) An introduction to kernel and nearest-neighbor nonparametric regression. Am Stat 46(3):175-185 
Andersson M, Larsson JP (2016) Local entrepreneurship clusters in cities. J Econ Geogr 16(1):39-66

Anderson AR, Obeng BA (2017) Enterprise as socially situated in a rural poor fishing community. J Rural Stud 49:23-31

Baltas G (2003) A combined segmentation and demand model for store brands. Eur J Mark 37(10):1499-1513

Beugelsdijk S (2007) Entrepreneurial culture, regional innovativeness and economic growth. J Evolut Econ 17(2):187-210

Bosma N, Schutjens Volker B (2016) Local social entrepreneurship and social capital. In: Westlund H, Larsson JP (eds) The handbook of social capital and regional development. Edward Elgar, Cheltenham, pp 55-81

Boterman WR (2018) A flavour of class-based spatial change: geographies of haute cuisine in the Netherlands. Tijdschr Econ Soc Geogr 109(1):161-170

Brülhart M, Mathys NA (2008) Sectoral agglomeration economies in a panel of European regions. Reg Sci Urban Econ 38(4):348-362

Caldas de Castro M, Singer BH (2006) Controlling the false discovery rate: a new application to account for multiple and dependent test in local statistics of spatial association. Geogr Anal 38:180-208

CDP (2017) The carbon majors database. CDP Carbon Majors Report 2017

Central Bureau for Statistics Netherlands (CBS) (2015) Bloemendaal and Wassenaar in 1930 already the wealthiest municipalities. https://www.cbs.nl/nl-nl/nieuws/2015/04/bloemendaal-en-wassenaar-ookal-in-1930-rijkste-gemeenten

Christaller W (1966) Central places in southern Germany. Prentice-Hall, Upper Saddle River

Cohen B (2006) Sustainable valley entrepreneurial ecosystems. Bus Strategy Environ 15(1):1-14

Cohen B, Muñoz P (2015) Toward a theory of purpose-driven urban entrepreneurship. Organ Environ 28(3):264-285

Daneke G, Hall J, Lenox M (2010) Sustainable development and entrepreneurship. J Bus Ventur 25(5):439-540

De Groot HLF, Poot J, Smit MJ (2016) Which agglomeration externalities matter most and why? J Econ Surv 30(4):756-782

De Lange DE (2016) A social capital paradox: entrepreneurial dynamism in a small world clean technology cluster. J Clean Prod 139:576-585

De Vaan M (2011) The connected firm: the spatial dimension of interorganizational dependence along the industry life cycle. University of Utrecht, Utrecht

Delgado M, Porter ME, Stern S (2010) Clusters and entrepreneurship. J Econ Geogr 10(4):495-518

Durlauf SN, Fafchamps M (2004) Social capital. National Bureau of Economic Research, Cambridge

Eko-Keurmerk Foundation (2018) Betrouwbaar Biologisch Buitenshuis (Reliable Organic Out-of-doors). http://www.eko-horeca.nl/. Accessed 23 Apr 2019

Estrin S, Mickiewicz T, Stephan U (2013) Entrepreneurship, social capital, and institutions: social and commercial entrepreneurship across nations. Entrep: Theory Pract 37(3):479-504

Etgar M, Rachman-Moore D (2010) Market and product diversification: the evidence from retailing. J Mark Channels 17(2):119-135

EuroStat (2019) Air pollution statistics-air emissions accounts. https://ec.europa.eu/eurostat/stati sticsexplained/index.php/Air_pollution_statistics_-_air_emissions_accounts\#General_overview. Accessed 23 Apr 2019

FAO (2006) Livestock's long shadow. Food and Agriculture Organization of the United Nations, Rome

Galkina T, Hultman M (2016) Ecopreneurship_assessing the field and outlining the research potential. Small Enterp Res 23(1):58-72

Garnett T (2014) What is a sustainable healthy diet?. Food Climate Research Network, Oxford

Gaspar JM (2018) A prospective review on New Economic Geography. Ann Reg Sci 61(2):237-272

Gast J, Gundolf K, Cesinger B (2017) Doing business in a green way: a systematic review of the ecological sustainability entrepreneurship literature and future research directions. J Clean Prod 147:44-56

Getis A, Ord JK (1992) The analysis of spatial association by use of distance statistics. Geogr Anal 24(3):189-206

Gössling S, Hall CM, Weaver DB (2009) Sustainable tourism futures: perspectives on systems, Restructuring and innovations. Routledge, New York

Hanohov R, Baldacchino L (2018) Opportunity recognition in sustainable entrepreneurship: an exploratory study. Int J Entrep Behav Res 24(2):333-358

Hart SL, Milstein MB (1999) Global sustainability and the creative destruction of industries. Sloan Manag Rev 41(1):23-33 
Hechavarría DM (2016) The impact of culture on national prevalence rates of social and commercial entrepreneurship. Int Entrep Manag J 12(4):1025-1052

Hofstede G (2001) Culture's consequences: comparing values, behaviors, institutions, and organizations across nations. Sage, Thousand Oaks

Hole DG, Perkins AJ, Wilson JD, Alexander IH, Grice PV, Evans AD (2005) Does organic farming benefit biodiversity? Biol Conserv 122:113-130

Huber F (2009) Social capital of economic clusters: towards a network-based conception of social resources. Tijdschrift Econ Soc Geogr 100(2):160-170

Huggins R, Thompson P (2017) The behavioral foundations of urban and regional development: culture, psychology and agency. J Econ Geogr 19(1):121-146

Isaak R (2002) The making of the ecopreneur. Greener Manag Int 38:81-91

Jacobs J (1969) The economy of cities. Vintage Books, New York

Johnsen CG, Olaison L, Sørensen BM (2018) Put your style at stake: a new use of sustainable entrepreneurship. Organ Stud 39(2-3):397-415

Kibler E, Kautonen T, Fink M (2014) Regional social legitimacy of entrepreneurship: implications for entrepreneurial intention and start-up behavior. Reg Stud 48(6):995-1015

Kibler E, Fink M, Lang R, Muñoz P (2015) Place attachment and social legitimacy: revisiting the sustainable entrepreneurship journey. J Bus Ventur Insights 3:24-29

Krueger N (1998) Sustainable entrepreneurship: broadening the definition of opportunity. J Organ Change Manag 11(2):174-183

Kuckertz A, Wagner M (2010) The influence of sustainability orientation on entrepreneurial intentionsinvestigating the role of business experience. J Bus Ventur 25(5):524-539

Lans T, Blok V, Wesselink R (2014) Learning apart and together: towards an integrated competence framework for sustainable entrepreneurship in higher education. J Clean Prod 62:37-47

Larsson R, Bowen DE (1989) Organization and customer: managing design and coordination of services. Acad Manag Rev 14(2):213-233

Laspita S, Breugst N, Heblich S, Patzelt H (2012) Intergenerational transmission of entrepreneurial intentions. J Bus Ventur 27(4):414-435

Litaa RP, Suryaa S, Ma'rufb M, Syahrula L (2014) Green Attitude and behavior of local tourists towards hotels and restaurants in West Sumatra, Indonesia. Procedia Environ Sci 20:261-270

Mackey J (2015) A debate on the social responsibility of business. In: Shaw WH, Barry V (eds) Moral issues in business. Cengage Learning, Boston, p 250

Mckeever E, Jack S, Anderson A (2015) Embedded entrepreneurship in the creative re-construction of place. J Bus Venturing 30(1):50-65

Milieucentraal (2018) Environmentally conscious eating. https://www.milieucentraal.nl/milieubewusteten/. Accessed April 142018

Moran PA (1950) Notes on continuous stochastic phenomena. Biometrika 37(1):17-23

Morawicki RO (2012) Handbook of sustainability for the food sciences. Wiley Blackwell, West Sussex

Muñoz P, Dimov D (2015) The call of the whole in understanding the development of sustainable ventures. J Bus Ventur 30(4):632-654

Muñoz P, Cohen B (2018) Sustainable entrepreneurship research: taking stock and looking ahead. Bus Strat Environ 27:300-322

Patzelt H, Shepherd DA (2011) Recognizing opportunities for sustainable development. Entrepr: Theory Pract 35(4):631-652

Phillips JC, Peterson HC (2001) Segmentation and differentiation of agri-food niche markets: examples from the literature. Department of Agricultural Economics, Michigan State University, Staff Paper \#2001-05

Plane DA (2016) Regional science in a physical/virtual more/less world. Ann Reg Sci 57(2):437-455

Ploum L, Blok V, Lans T, Omta O (2018) Toward a validated competence framework for sustainable entrepreneurship. Organ Environ 31(2):113-132

Porter ME (1990) The competitive advantage of nations. Macmillan, London

Portes A (2000) The two meanings of social capital. Sociol Forum 15(1):1-12

Raab C, Baloglu S, Chen YS (2018) Restaurant managers' adoption of sustainable practices: an application of institutional theory and theory of planned behavior. J Foodserv Bus Res 21(2):154-171

Romer PM (1986) Increasing Returns and long-run growth. J Polit Econ 94(5):1002-1037

Sarmiento CV, Hanandeh AE (2018) Customers' perceptions and expectations of environmentally sustainable restaurant and the development of green index: the case of the Gold Coast, Australia. Sustain Prod Consum 15(2018):16-24 
Saxenian A (1996) Inside-out: regional networks and industrial adaptation in Silicon Valley and Route 128. Cityscape 2(2):41-60

Schick H, Marxen S, Freimann J (2002) Sustainability Issues for start-up entrepreneurs. Greener Manag Int 38:59-70

Schiff N (2015) Cities and product variety: evidence from restaurants. J Econ Geogr 15(6):1085-1123

Schwartz SH, Bilsky W (1990) Toward a theory of the universal content and structure of values: extensions and cross-cultural replications. J Pers Soc Psychol 58(5):878-891

Shane S, Venkataraman S (2000) The promise of entrepreneurship as a field of research. Acad Manag Perspect 25(1):217-226

Shrivastava P, Kennelly JJ (2013) Sustainability and place-based enterprise. Organ Environ 26(1):83-101

Simon M, Miree C, Dule M (2013) La Vida local: planting the seeds for growing an organic food delivery business. Entrepr: Theory Pract 37(3):641-660

Spence M, Gherib JBB, Biwolé VO (2011) Sustainable entrepreneurship: is entrepreneurial will enough? A north-south comparison. J Bus Ethics 99(3):335-367

Sternberg R, Litzenberger T (2004) Regional clusters in Germany-their geography and their relevance for entrepreneurial activities. Eur Plan Stud 12(6):767-791

Sunny SA, Shu C (2019) Investments, incentives, and innovation: geographical clustering dynamics as drivers of sustainable entrepreneurship. Small Bus Econ 52(4):905-927

Thompson H (1998) Marketing strategies: what do your customers really want. J Bus Strat 19(4):16-21

Tran HT, Santarelli E (2017) Spatial heterogeneity, industry heterogeneity, and entrepreneurship. Ann Reg Sci 59(1):69-100

Uhlaner L, Thurik R (2007) Postmaterialism influencing total entrepreneurial activity across nations. J Evol Econ 17:161-185

Van Oort FG (2007) Spatial and sectoral composition effects of agglomeration economies in the Netherlands. Pap Reg Sci 86(1):5-30

Venkataraman S (1997) The distinctive domain of entrepreneurship research: An editor's perspective. In: Katz J, Brockhaus R (eds) Advances in entrepreneurship, vol. 3: firm emergence and growth. JAI Press, Greenwich, pp 119-138

Voedingscentrum (2018) Environment and climate. http://www.voedingscentrum.nl/encyclopedie/milie uenklimaat.aspx. Accessed April 142018

WWF (2016) Living planet report 2016. Risk and resilience in a new era. WWF International, Gland, Switzerland

Xu Y, Jeong E (2019) The effect of message framings and green practices on customers' attitudes and behavior intentions toward green restaurant. Int J Contemp Hosp Manag 31(6):2270-2296

York JG, O’Neil I, Sarasvathy SD (2016) Exploring environmental entrepreneurship: identity coupling, venture goals, and stakeholder incentives. J Manag Stud 53(5):695-737

Zukin S (1995) The culture of cities. Blackwell, Cambridge

Publisher's Note Springer Nature remains neutral with regard to jurisdictional claims in published maps and institutional affiliations. 